\title{
Changes in Ventilation and Oxygen Consumption during Acute Hypoxia in Sedated Newborn Piglets
}

\author{
CLEIDE SUGUIHARA, EDUARDO BANCALARI, DOROTHY HEHRE, SHAHNAZ DUARA, AND \\ TILO GERHARDT \\ Department of Pediatrics, Division of Neonatology. University of Miami School of Medicine, \\ Miami, Florida 33101
}

\begin{abstract}
The purpose of this study was to evaluate the relationship between changes in minute ventilation $\left(\dot{V}_{E}\right)$ and oxygen consumption $\left(\dot{\mathrm{VO}}_{2}\right)$ in response to acute hypoxia in the newborn piglet. Twenty-five (mean $\pm \mathrm{SD}$; age, $4.7 \pm 1.1 \mathrm{~d}$; weight, $1451 \pm 320 \mathrm{~g}$ ) sedated, spontaneously breathing newborn piglets were studied. $\dot{V}_{E}$ was measured by pneumotachography, and $\dot{\mathrm{VO}}_{2}$ was measured by the open-circuit technique. Measurements were performed while the animals breathed room air and repeated after $\mathbf{1 0}$ min of hypoxia, which was induced by breathing $10 \%$ oxygen. Although the mean $\dot{V}_{E}$ values during hypoxia displayed a typical biphasic ventilatory response, the individual pattern of this ventilatory response to hypoxia was variable. Thirteen animals sustained $\dot{V}_{E}$ above baseline after 10 min of hypoxia, whereas the 12 remaining animals decreased $\dot{V} E$ after 10 min of hypoxia to values below their room air baseline. The $\dot{\mathrm{V}}_{2}$ values did not differ between groups during normoxia, and a similar decrease in $\mathrm{V}_{2}$ occurred in both groups after $\mathbf{1 0} \mathrm{min}$ of hypoxia. Furthermore, no correlation was observed between changes in $\dot{V}_{E}$ and $\mathrm{VO}_{2}$ during hypoxia either in absolute values or in the percent change from room air baseline. Arterial $\mathrm{PO}_{2}$ decreased similarly in both groups, but $\mathrm{PaCO}_{2}$ decreased significantly only in the group that sustained $\dot{V}_{E}$ above baseline after $10 \mathrm{~min}$ of hypoxia. These data demonstrate that in this animal model the hypoxic ventilatory depression is not determined by the decrease in $\dot{V}_{2}$ that occurs during hypoxia. (Pediatr Res 35: 536-540, 1994)
\end{abstract}

\section{Abbreviations}

ABP, arterial blood pressure

HR, heart rate

$\mathrm{CO}$, cardiac output

VE, minute ventilation

$\dot{\mathrm{V}}_{2}$, oxygen consumption

VT, tidal volume

$\mathrm{PaO}_{2}$, partial pressure of oxygen, arterial

$\mathrm{PaCO}_{2}$, partial pressure of carbon dioxide, arterial

The ventilatory response to hypoxia in the neonatal period in human beings and several animal species is characterized by a transient period of hyperventilation (1-2 $\mathrm{min}$ ), followed by a marked decline in $\dot{V}_{E}$ to values slightly above or below the

Received August 5, 1993; accepted December 29, 1993.

Correspondence. Cleide Suguihara, M.D. University of Miami School of Medicine, Department of Pediatrics (R-131), P.O. Box 016960, Miami. FL 33101.

Supported by the University of Miami: Project New Born. prehypoxia level (1-4). The exact mechanism responsible for the lack of sustained hyperventilation during hypoxia in the neonate has not been explained. Release of depressant neurotransmitters or neuromodulators $(2,5-10)$, brain stem alkalosis caused by an increase in cerebral blood flow (11), changes in lung mechanics (12), respiratory muscle fatigue (3), or inhibition of peripheral chemoreceptors (13) have been suggested as possible causes of the hypoxic ventilatory depression. The human adult also has a biphasic ventilatory response to hypoxia, but the initial increase in ventilation is sustained for $10-20 \mathrm{~min}$, and although it is followed by a decrease in $\dot{V}_{\mathrm{E}}$, the latter level remains well above the baseline values (14).

Cross $c t$ al. (15) observed that preterm infants had a decrease in metabolic rate accompanying hypoventilation during acute hypoxia. Extending these findings, Mortola and Rezzonico (16) reported a tight coupling between decreases in ventilation and metabolism in newborn kittens exposed to acute hypoxia. These results suggest that the late decrease in ventilation observed in neonates during hypoxia may be at least in part related to a decrease in the metabolic rate, possibly mediated by a fall in body temperature $(16,17)$.

The piglet is a relatively mature animal at birth compared with the human infant and the newborn kitten. However, the ventilatory response to hypoxia in this species is variable, and although some animals respond with sustained hyperventilation similar to the adult response, other animals of similar age have an immature type of response with a decrease in $\dot{V}_{E}(4,18)$. Although several factors may contribute to this variability, the exact mechanism remains unknown. The possibility that this variability may be related to differences in the metabolic response to hypoxia has not been explored. The neonatal piglet model provided us with the opportunity to study the metabolic response to hypoxia in animals with differences in the ventilatory response to hypoxia and to evaluate the relationship between the changes in the metabolic rate and the ventilatory response to hypoxia.

\section{MATERIALS AND METHODS}

Twenty-five piglets $7 \mathrm{~d}$ of age or younger were anesthetized with ketamine $(20 \mathrm{mg} / \mathrm{kg}$ intramuscularly) and xylazine $(2 \mathrm{mg} /$ $\mathrm{kg}$ intramuscularly) for surgical procedures and then sedated with chloral hydrate, $100 \mathrm{mg} / \mathrm{kg}$ injected intraperitoneally. Chloral hydrate administration was repeated at a dose of 25-50 $\mathrm{mg} / \mathrm{kg}$ intraperitoneally at intervals of 3 to $4 \mathrm{~h}$, in response to signs of arousal in the animal (opening of eyes, movement of limbs or ears). Sedation was kept sufficiently light so as to allow arousal with increase in environmental noise and preservation of the eyelash blink (19). Lidocaine hydrochloride $(0.5 \%)$ was used for local anesthesia. Experimental trials were commenced at least $2 \mathrm{~h}$ after the administration of ketamine. The left femoral artery and vein were cannulated and used for systemic ABP and 
HR measurements, blood sampling, and infusion of fluids. The left external jugular vein was cannulated and the catheter advanced into the right atrium for injection of cold saline for the measurement of CO. A 5F Swan-Ganz catheter was introduced into the right external jugular vein and advanced under fluoroscopy into the left pulmonary artery. $\mathrm{CO}$ was measured by thermodilution with a CO computer (95510-A, Edwards Laboratory, Santa Ana, CA). Vascular pressures were measured with pressure transducers (model P23-ID; Gould Instruments, Cleveland, $\mathrm{OH}$ ) and recorded on a multichannel recorder (model 3800, Gould Instruments).

A tracheostomy was performed, and a $3.5-\mathrm{mm}$ endotracheal tube was inserted and secured at the insertion site with a strong silk tie so as to prevent air leak. Respiratory flow was measured by a heated Fleisch No. 00 pneumotachograph (OEM Medical, Richmond, VA), a differential pressure transducer (model MP45, Validyne Engineering Co., Northridge, CA), and a pressure amplifier (Gould Instruments). The flow signal was electronically integrated to obtain VT with a Gould integrator amplifier. Calibration of $V_{T}$ was performed before and after each study with a calibrated glass syringe. $\dot{V}_{E}$ was obtained by a summation of the inspiratory volumes measured during 1 -min periods of regular respiration. Airflow and VT were recorded on a multichannel recorder (Model 3800; Gould Instruments).

$\dot{\mathrm{V}}_{2}$ was measured by the open-circuit technique $(19,20)$. A constant bias flow of $3-4 \mathrm{~L} / \mathrm{min}$ of heated and humidified room air or $10 \% \mathrm{O}_{2}$ was delivered through the breathing circuit, and the difference between inspiratory and expiratory $\mathrm{O}_{2}$ concentration was continuously measured with an oxygen analyzer (model 570-A, Servomex, Crowborough, Sussex, UK), which has an accuracy of $\pm 0.1 \%$. $\dot{V}_{2}$ was calculated by the formula: $\dot{\mathrm{V}}_{2}=$ $\dot{\mathrm{V}} \mathrm{s} \cdot\left(\mathrm{FIO}_{2}-\mathrm{FEO}_{2}\right)$ at body temperature and ambient pressure and saturated with water vapor (gas), where Vs is the flow rate through the system, $\mathrm{FIO}_{2}$ is the fraction of inspired oxygen concentration, and $\mathrm{FEO}_{2}$ is the fraction of oxygen in mixed expired gas. The flow rate through the system was measured before each run by a Matheson linear mass flowmeter $(0.0-20.0 \mathrm{~L} / \mathrm{min}$, model 8100 , Matheson Gas Products, Secaucus, NJ).

To determine whether the $\mathrm{VO}_{2}$ values obtained by open-circuit technique were accurate, the $\dot{\mathrm{V}}_{2}$ measured during room air and hypoxia was compared with that obtained by the Fick method in seven animals. Simultaneous arterial and central venous (Swan-Ganz catheter) samples were obtained to measure arterial $\left(\mathrm{CaO}_{2}\right)$ and venous $\left(\mathrm{CvO}_{2}\right)$ oxygen contents by a cooximeter (IL482, Instrumentation Laboratory, Pittsburgh, PA). $\dot{\mathrm{V}}_{2}$ was calculated using the following formula: $\mathrm{VO}_{2}=\mathrm{CO}\left(\mathrm{CaO}_{2}-\mathrm{CvO}_{2}\right) \times$ 10.

The skin temperature was maintained at $38.5^{\circ} \mathrm{C}$ by means of a servocontrolled radiant warmer. The rectal temperature was continuously monitored with a thermistor probe. The animals received an infusion of $6 \mathrm{~mL} / \mathrm{kg} / \mathrm{h}$ of $5 \%$ dextrose solution through a peripheral vein and $2.5 \mathrm{~mL} / \mathrm{h}$ of heparinized saline solution $(10 \mathrm{U} / \mathrm{mL})$ through the pulmonary artery catheter.

To evaluate the effect of two different thermal conditions on the $\dot{\mathrm{V}}_{2}$ and ventilation during hypoxia, a separate group of four newborn piglets were studied while servocontrolling skin temperature to $38.5^{\circ} \mathrm{C}$ under a radiant warmer and again while maintaining a constant environmental temperature at $34^{\circ} \mathrm{C}$ in an isolette. This temperature has been previously established as the thermoneutral environment for newborn piglets (21).

Blood $\mathrm{Hb}$ concentration was determined by the cyanmethemoglobin method (22).

Induction of hypoxia. The animals were allowed a 90-min stabilization period after completion of surgery (usually lasting $30-45 \mathrm{~min}$ ). After this period, the animals were connected to a breathing circuit with a constant bias flow of 3-4 L/min, which was slightly higher than the peak flow of the animals $(2.5-3.5 \mathrm{~L} /$ $\mathrm{min}$ ). After $10 \mathrm{~min}$ of basal recording in room air, $\dot{\mathrm{V}} \mathrm{E}, \mathrm{ABP}, \mathrm{CO}$, $\grave{\mathrm{V}}_{2}$, and arterial blood gas measurements were obtained and referred to as room air baseline measurements. To induce hy- poxia, we reduced the fraction of inspired oxygen to 0.10 with an oxygen balance nitrogen gas mixture. After 10 min of hypoxia, all measurements were immediately repeated. Average values for $\dot{V} \mathrm{E}$ and $\dot{\mathrm{V}}_{2}$ were obtained from the last $5 \mathrm{~min}$ of collected data in room air. $\dot{V}_{E}$ and $\dot{V}_{\mathrm{O}_{2}}$ values at 5 and $10 \mathrm{~min}$ of hypoxia were calculated from values collected between 4 to $6 \mathrm{~min}$ and between 9 to $11 \mathrm{~min}$ of hypoxia, respectively. The animals then were returned to room air, and all measurements were repeated. Measurements were not performed if animals were judged to be in active sleep as evaluated by behavioral criteria (23) or showed signs of distress as evidenced by unstable HR or sinusoidal ABP wave form. In addition, all measurements were obtained when environmental noise was at ambient baseline.

Study animals $(n=25)$ were then divided into two groups: those whose $\dot{V}_{E}$ increased and those whose $\dot{V}_{E}$ decreased when exposed to $10 \%$ oxygen. The $\uparrow \dot{V}_{E}$ group was composed of animals who maintained $\dot{V}_{E}$ at levels higher than baseline values after $10 \mathrm{~min}$ of hypoxia, and the animals whose $\dot{V}_{E}$ decreased to values at or below their baseline values after $10 \mathrm{~min}$ of hypoxia were included in the $\downarrow \dot{V}_{E}$ group. These two types of response were anticipated because of our previous experience (18); the separation was conducted to analyze in more detail possible factors that could have contributed to the differences in the ventilatory response to hypoxia in this neonatal animal model.

Data analysis. Results of the cardiovascular, metabolic, and respiratory measurements obtained during normoxia and hypoxia were compared by the paired $t$ test. Bonferroni correction was used when multiple comparisons were performed. The correlation between $\dot{V} E$ and $\dot{V}_{2}$ was evaluated by linear regression analysis.

Repeated-measures analysis of variance was used to compare the changes in $\dot{\mathrm{V}}_{\mathrm{E}}$ and $\dot{\mathrm{V}}_{2}$ during hypoxia between the $\uparrow \dot{\mathrm{V}}_{\mathrm{E}}$ and $\downarrow \dot{V}_{E}$ groups. A one-way analysis of variance was used to compare the arterial blood gas values and respiratory variables between the two groups of animals. A $p<0.05$ was considered statistically significant.

\section{RESULTS}

The values for arterial blood gases, cardiovascular measurements, $\dot{V}_{\mathrm{E}}$, and $\dot{\mathrm{V}}_{2}$ for the entire group are shown in Table 1. After 10 min of hypoxia, mean $\mathrm{pH}$ and $\mathrm{PaCO}_{2}$ remained unchanged, and $\mathrm{PaO}_{2}$ decreased significantly. Mean $\mathrm{CO}$ increased significantly with hypoxia, whereas ABP did not change.

After 10 min of hypoxia, mean VE was not statistically different from baseline room air values when all animals were evaluated as a single group. Mean $\dot{V}_{E}$ increased by $25.6 \pm 18.4 \%$ during the 1st min of hypoxia, followed by a decline to $6.4 \pm 14 \%$ above room air values after $10 \mathrm{~min}$ of hypoxia. The mean and $95 \%$ confidence interval for the difference in $\dot{V}_{E}$ from baseline room

Table 1. Measurements obtained during normoxia before and after hypoxia exposure and after 10 min of hypoxia for 25 animals*

\begin{tabular}{lccc}
\hline & Room air & $10 \% \mathrm{O}_{2}$ & Room air $_{2}$ \\
\hline $\mathrm{pH}$ & $7.40 \pm 0.04$ & $7.40 \pm 0.05$ & $7.40 \pm 0.04$ \\
$\mathrm{PaO}_{2}(\mathrm{kPa})$ & $10.9 \pm 1.3$ & $3.7 \pm 0.4 \dagger$ & $10.9 \pm 1.5$ \\
$\mathrm{PaCO}_{2}(\mathrm{kPa})$ & $5.2 \pm 0.6$ & $5.0 \pm 0.7$ & $5.0 \pm 0.5$ \\
$\mathrm{HCO}_{3}^{-}(\mathrm{mmol} / \mathrm{L})$ & $23 \pm 3$ & $23 \pm 3$ & $23 \pm 3$ \\
$\mathrm{CO}(\mathrm{L} / \mathrm{min} / \mathrm{kg})$ & $0.24 \pm 0.07$ & $0.32 \pm 0.08 \dagger$ & $0.25 \pm 0.06$ \\
$\mathrm{Mean} \mathrm{ABP}(\mathrm{mm} \mathrm{Hg})$ & $47 \pm 7$ & $50 \pm 9$ & $46 \pm 5$ \\
$\mathrm{HR}($ beats $/ \mathrm{min})$ & $196 \pm 30$ & $222 \pm 40 \dagger$ & $201 \pm 29$ \\
$\mathrm{RR}(\mathrm{breaths} / \mathrm{min})$ & $68 \pm 21$ & $65 \pm 19$ & $67 \pm 22$ \\
$\mathrm{VT}(\mathrm{mL} / \mathrm{kg})$ & $6.4 \pm 1.3$ & $7.1 \pm 1.5$ & $6.8 \pm 1.5$ \\
$\dot{\mathrm{V}}_{\mathrm{E}}(\mathrm{mL} / \mathrm{min} / \mathrm{kg})$ & $416 \pm 94$ & $435 \pm 86$ & $420 \pm 99$ \\
$\dot{\mathrm{O}}_{2}(\mathrm{~mL} / \mathrm{min} / \mathrm{kg})$ & $8.8 \pm 1.5$ & $8.0 \pm 1.2 \dagger$ & $8.7 \pm 1.0$ \\
\hline
\end{tabular}

* Mean \pm SD. Room air ${ }_{1}$, room air before hypoxia exposure; room air $_{2}$, room air after hypoxia exposure; RR, respiratory rate.

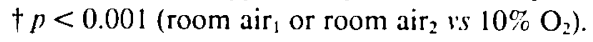


air to $10 \mathrm{~min}$ of hypoxia was $19 \pm 22 \mathrm{~mL} / \mathrm{min} / \mathrm{kg}$. During hypoxia, $\mathrm{VO}_{2}$ decreased from $8.8 \pm 1.5$ to $8.0 \pm 1.2 \mathrm{~mL} / \mathrm{min} /$ $\mathrm{kg}$, which was $7.3 \pm 9.6 \%$ below room air baseline value $(p<$ 0.001 ).

As expected on the basis of our previous findings in this model, the ventilatory response to hypoxia was variable. Thirteen animals (age, $4.8 \pm 1.4 \mathrm{~d}$; weight, $1528 \pm 209 \mathrm{~g}$ ) maintained a sustained increase in $\dot{V}_{E}$ after 10 min of hypoxia ( $\uparrow \dot{V}_{E}$ group), whereas the remaining 12 animals (age, $4.3 \pm 1.2 \mathrm{~d}$; weight, 1367 $\pm 402 \mathrm{~g}$ ) had $\dot{V}_{E}$ at or below baseline after $10 \mathrm{~min}$ of hypoxia ( $\downarrow \dot{V} E$ group). For this reason the results were also analyzed separately for the two groups (Table 2). The decrease in $\mathrm{PaO}_{2}$ while breathing $10 \%$ oxygen was similar in both groups, but $\mathrm{PaCO}_{2}$ decreased only in the group of animals with persistent hyperventilation during hypoxia ( $\uparrow \dot{\mathrm{V}} \mathrm{E}$ group). No differences in $\mathrm{CO}, \mathrm{HR}$, and mean ABP under normoxic conditions were observed between the two groups of animals, and $\mathrm{CO}$ and $\mathrm{HR}$ increased significantly during hypoxia in both groups. However, mean ABP increased with hypoxia only in those animals who showed a sustained elevation in ventilation $(\uparrow \dot{\mathrm{V}} \mathrm{E}$ group, $p<$ 0.02 ). Cardiorespiratory measurements and arterial blood gas values obtained in room air after hypoxia exposure did not differ from the room air baseline, eliminating time as a contributing factor for the observed changes in these variables during hypoxia (Tables 1 and 2). Hb concentration did not differ between groups.

Mean VE after 5 and $10 \mathrm{~min}$ of hypoxia remained $21 \pm 11 \%$ and $18 \pm 3 \%$ above baseline, respectively, in the $\uparrow \dot{V}_{E}$ group, whereas in the $\downarrow \dot{V}$ E group values decreased to $5 \pm 8 \%$ and $7 \pm$ $1 \%$ below baseline, respectively $(p<0.001)$ (Fig. $1 A)$.

Mean $\dot{\mathrm{V}}_{2}$ was similar in both groups during normoxia. In comparison to baseline, the decrease in $\dot{\mathrm{V}}_{2}$ after $5 \mathrm{~min}$ of hypoxia was $7 \pm 10 \%$ in the $\uparrow \dot{V}_{E}$ group, whereas in the $\downarrow \dot{V}_{E}$ group it was $11.8 \pm 8.3 \%$ (Fig. $1 B$ ). The decrease in $\dot{V}_{\mathrm{O}_{2}}$ after $10 \mathrm{~min}$ of hypoxia was similar in both groups $(7.2 \%$ versus $7.5 \%)$ irrespective of the type of ventilatory response. No correlation was found between the individual changes in $\dot{\mathrm{V}}_{\mathrm{E}}$ and $\dot{\mathrm{V}}_{2}$ with hypoxia either as absolute values or in percent change from baseline (Fig. 2).

During normoxia, mean $\dot{\mathrm{V}}_{2}$ was similar when measured by the open-circuit technique and the Fick method $(8.4 \pm 1.4$ versus $8.6 \pm 1.6 \mathrm{~mL} / \mathrm{kg} / \mathrm{min})$. Furthermore, the changes in $\dot{\mathrm{V}}_{\mathrm{O}_{2}}$ with hypoxia were not different when measured by the open-circuit technique and the Fick method $(-9.1 \pm 9.5 \%$ versus $-9.2 \pm$ $10.5 \%)$. A significant linear correlation between both methods $(p<0.0001)$ with an $r$ of 0.92 was observed.

Changes in $\dot{\mathrm{V}} \mathrm{E}$ and $\dot{\mathrm{V}}_{2}$ after exposure to $10 \mathrm{~min}$ of hypoxia were similar in the four animals studied under two different thermal conditions. With servocontrol of skin temperature, mean $\dot{\mathrm{V}} \mathrm{E}$ increased $11 \pm 1 \%$, and $\dot{\mathrm{V}}_{2}$ decreased $9.2 \pm 1.3 \%$ after 10 min of hypoxia in comparison with room air baseline values, whereas at a constant environmental temperature, mean $\dot{V}_{E}$ increased $11 \pm 1 \%$ and $\mathrm{VO}_{2}$ decreased $9.1 \pm 0.6 \%$ after $10 \mathrm{~min}$ of hypoxia.

Rectal temperature was not different between the $\uparrow \dot{\mathrm{V}}_{\mathrm{E}}(n=$ 13) and $\downarrow \dot{V}_{E}(n=12)$ groups during normoxia with skin temperature under servocontrol; both groups of animals showed a similar decrease of $0.1^{\circ} \mathrm{C}$ in rectal temperature after $10 \mathrm{~min}$ of hypoxia. Rectal temperature decreased $0.2^{\circ} \mathrm{C}$ during hypoxia in the animals studied under a constant thermal environment $(n=$ 4 ), and rectal temperature decreased $0.1^{\circ} \mathrm{C}$ when the same animals were studied during servocontrol of the skin.

The total dose of chloral hydrate used and the time period elapsed between the last dose and beginning of the study period were similar in the $\uparrow \dot{V}_{E}$ and $\downarrow \dot{V} E$ animals $(142 \pm 62 \mathrm{mg} / \mathrm{kg}$ and $76 \pm 37 \mathrm{~min}$ versus $135 \mathrm{mg} / \mathrm{kg}$ and $72 \pm 27 \mathrm{~min}$ ), making these factors less likely to be contributors to the variability in the ventilatory response to hypoxia.

\section{DISCUSSION}

The present data do not support the hypothesis that a reduction in $\mathrm{VO}_{2}$ during hypoxia is responsible for the late decrease in ventilation observed during hypoxia in sedated newborn piglets. No correlation was observed between changes in $\dot{\mathrm{V}}_{2}$ and $\dot{\mathrm{V}}_{\mathrm{E}}$ with hypoxia in the study animals independent of their ventilatory response.

A decrease in $\dot{\mathrm{V}}_{2}$ during hypoxia has been demonstrated in a number of previous studies in newborn human beings and animals and has been suggested as a possible explanation for the late hypoxic decrease in ventilation $(15,16,24,25)$. In contrast, the present study demonstrates that the reduction in VE did not correlate with the change in $\dot{\mathrm{VO}}_{2}$ because a comparable decrease in $\mathrm{V}_{2}$ occurred in the two groups of animals despite differences in the pattern of ventilation during acute hypoxia. Although the decrease in the metabolic rate may have influenced the modulation of the ventilatory response to hypoxia, a change in the metabolic rate alone is not a satisfactory explanation for the ventilatory depression observed in these animals.

The lack of correlation between the changes in $\dot{\mathrm{V}}_{2}$ and $\dot{\mathrm{V}}_{\mathrm{E}}$ during hypoxia in the present study is in contrast to what has been previously reported $(15,16)$. This finding may in part be related to the differences in the thermal conditions used in the earlier studies and also to species differences. Whereas Mortola and Rezzonico (16) studied newborn kittens at constant environmental temperature, in the present study we studied piglets that are more mature at birth, with their skin temperature maintained at a constant level by a servocontrolled radiant heater. This thermal difference may in part account for the smaller drop in $\dot{\mathrm{VO}}_{2}(7 \%)$ observed during hypoxia when compared with that reported in newborn kittens $(65 \%)$ because the fall in rectal

Table 2. Measurements obtained during normoxia before and after hypoxia exposure and after 10 min of hypoxia by group*

\begin{tabular}{|c|c|c|c|c|c|c|}
\hline & \multicolumn{3}{|c|}{$\uparrow \dot{\mathrm{V}}_{\mathrm{E}}(n=13)$} & \multicolumn{3}{|c|}{$\downarrow \dot{\mathrm{V}} \mathrm{E}(n=12)$} \\
\hline & Room air, & $10 \% \mathrm{O}_{2}$ & Room air $_{2}$ & Room air ${ }_{1}$ & $10 \% \mathrm{O}_{2}$ & Room air 2 \\
\hline $\mathrm{pH}$ & $7.39 \pm 0.04$ & $7.41 \pm 0.06$ & $7.38 \pm 0.04$ & $7.41 \pm 0.03$ & $7.39 \pm 0.04$ & $7.42 \pm 0.04$ \\
\hline $\mathrm{PaO}_{2}(\mathrm{kPa})$ & $10.9 \pm 1.3$ & $3.6 \pm 0.4 \dagger$ & $11.1 \pm 1.5$ & $10.9 \pm 1.4$ & $3.7 \pm 0.4 \dagger$ & $10.7 \pm 1.5$ \\
\hline $\mathrm{PaCO}_{2}(\mathrm{kPa})$ & $5.3 \pm 0.7$ & $4.7 \pm 0.7 \ddagger$ & $5.1 \pm 0.6$ & $5.2 \pm 0.5$ & $5.2 \pm 0.6$ & $5.0 \pm 0.3$ \\
\hline $\mathrm{HCO}_{3}^{-}(\mathrm{mmol} / \mathrm{L})$ & $23 \pm 3$ & $22 \pm 4$ & $22 \pm 3$ & $24 \pm 3$ & $23 \pm 3$ & $24 \pm 2$ \\
\hline Mean ABP $(\mathrm{mm} \mathrm{Hg})$ & $47 \pm 7$ & $54 \pm 9 \ddagger$ & $46 \pm 6$ & $48 \pm 8$ & $46 \pm 7$ & $46 \pm 5$ \\
\hline $\mathrm{CO}(\mathrm{L} / \mathrm{min} / \mathrm{kg})$ & $0.26 \pm 0.06$ & $0.34 \pm 0.07 \dagger$ & $0.26 \pm 0.05$ & $0.22 \pm 0.07$ & $0.28 \pm 0.09 \dagger$ & $0.23 \pm 0.07$ \\
\hline HR (beats/min) & $199 \pm 28$ & $225 \pm 37 \dagger$ & $201 \pm 27$ & $192 \pm 22$ & $218 \pm 44 \dagger$ & $201 \pm 32$ \\
\hline RR (breaths/min) & $62 \pm 23$ & $63 \pm 22$ & $61 \pm 18$ & $74 \pm 16$ & $67 \pm 15 \ddagger$ & $70 \pm 27$ \\
\hline $\mathrm{VT}(\mathrm{mL} / \mathrm{kg})$ & $6.7 \pm 1.6$ & $7.5 \pm 1.4 \ddagger$ & $6.8 \pm 1.4$ & $6.2 \pm 0.9$ & $6.6 \pm 1.5$ & $6.8 \pm 1.7$ \\
\hline$\dot{\mathrm{V}}_{\mathrm{E}}(\mathrm{mL} / \mathrm{min} / \mathrm{kg})$ & $383 \pm 101$ & $444 \pm 104 \dagger$ & $390 \pm 99$ & $452 \pm 76$ & $425 \pm 66 \dagger$ & $450 \pm 94$ \\
\hline$\dot{\mathrm{V}}_{\mathrm{O}_{2}}(\mathrm{~mL} / \mathrm{min} / \mathrm{kg})$ & $9.2 \pm 1.6$ & $8.4 \pm 1.2 \ddagger$ & $9.0 \pm 1.1$ & $8.4 \pm 1.2$ & $7.7 \pm 0.9 \ddagger$ & $8.5 \pm 0.9$ \\
\hline
\end{tabular}

* Mean \pm SD; room air $_{1}$, room air before hypoxia exposure; room air $r_{2}$, room air after hypoxia exposure; $R R$, respiratory rate.

$\dagger p<0.005$ (room air or $_{1}$ room air 2 's $10 \% \mathrm{O}_{2}$ ).

$\ddagger p<0.02$ (room air or room air $_{2}$ is $10 \% \mathrm{O}_{2}$ ). 